\title{
O UNIVERSO PARALELO DAS GRAVADORAS INDEPENDENTES NA CIDADE DE
}

\section{CURITIBA}

\author{
Bruno de Paula Seus ${ }^{1}$ \\ Geovanna Lucas Mussak ${ }^{2}$ \\ Patrícia Marcondes de Barros $^{3}$
}

\section{Resumo}

O presente artigo tem como objetivo abordar os principais meios de produção e divulgação das gravadoras independentes na cidade de Curitiba. Para tanto, abordamos a história da indústria fonográfica e a busca por espaços alternativos para iniciativas independentes no Brasil. Em seguida, analisamos o contexto de produção musical na cidade de Curitiba, especificamente, das gravadoras independentes que têm como desafio constante manter-se ativas num mercado cada vez mais competitivo.

Palavras-chave: História da mídia, música, indústria fonográfica, gravadoras independentes.

\section{Abstract}

The aim of this article is to study the main means of production and diffusion adopted by independent recording companies in Curitiba. In order to do so, we focus on the history of the recording industry and the search of alternative spaces by independent producers in Brazil. Then, we analyze the context of musical production in Curitiba, regarding mainly independent recording labels and their search for a position in a very competitive market.

Keywords: Media history, music, recording industry, independent recording labels.

\section{Introdução}

Num ambiente competitivo e tomado por poderosas gravadoras, a indústria musical se torna totalmente desproporcional atingindo, diretamente, as gravadoras independentes que, de forma geral, trabalham de maneira simples e eficiente, apresentando uma produção alternativa aos interesses comerciais.

Dentro de um cenário onde a indústria fonográfica comandava os artistas que se destacava na mídia, Lobão foi um dos precursores da gravação independente no Brasil, mudando completamente os padrões de produção, divulgação e circulação da música. Ao se deparar com várias rejeições de suas canções, criou maneiras de produzir aquilo que desejava sem o aparato comercial das grandes gravadoras. Depois de gravar as músicas do álbum “A

\footnotetext{
${ }^{1}$ Graduado em Publicidade e Propaganda pela Universidade Positivo.

${ }^{2}$ Graduada em Publicidade e Propaganda pela Universidade Positivo.

${ }^{3}$ Doutora em História Cultural pela Universidade Estadual Paulista “Julio de Mesquita Filho" (UNESP).
} 
vida é doce" (1999), lançou seu disco em uma revista, pois não havia tributação para produtos editoriais, além de ter ampla distribuição nas bancas de revista. Nomeou o selo como "Universo Paralelo" e a revista, que encartou o disco de "Lobão Manifesto", lançada em 1999, despertou grande interesse na cena independente, repercutindo de tal forma que por três anos proferiu palestras sobre sua empreitada.

Diante dessa situação, procurar-se-á entender como ocorreu o desdobramento desse fato no resto do Brasil, especificamente na cidade de Curitiba, tendo como base o início da indústria fonográfica e sua função como produtora e distribuidora da música gravada.

\section{Devires da indústria fonográfica brasileira}

Desde que foi inventado um aparelho para a reprodução de sons, o homem vem buscando novas tecnologias para tornar mais eficiente sua propagação. O primeiro aparelho gravador de sons, denominado fonógrafo, foi inventado por Thomas Edison, em 1877. Nele, usava-se um cilindro com papel laminado para realizar as gravações. A gravação do som é a estocagem das vibrações produzidas no ar pelo som, e para sua reprodução o inverso acontece - as vibrações estocadas se convertem em ondas sonoras. Apesar de inovador, o fonógrafo tinha algumas limitações, como a impossibilidade de cópias, além da imperfeição da reprodução (SILVA, 2010).

Conforme observa Piccino (2003), o alemão Emile Berliner é quem desenvolve o sistema de microfonagem para telefones e que, em 1888, patenteia e constrói o gramofone, com a colaboração do mecânico Eldridge Johnson. Este aparelho passou a ser comercializado nos Estados Unidos em 1896. É com o microfone que vai ser possível ter uma nova forma de cantar, em que os amplificadores e alto-falantes vão proporcionar aos ouvintes uma melhor compreensão e apreciação da música além do seu possível registro (PICCINO, 2003, p. 13).

De acordo com a professora Simone de Sá (UFF), é em meados dos anos 1920 que surge a gravação elétrica, permitindo uma grande melhora na qualidade do som, no formato de disco de ebonite de 10 polegadas, de 78 r.p.m., registrando aproximadamente quatro minutos em cada um dos lados. A invenção foi chamada de Long Play ou simplesmente LP, e foi lançada pela marca Columbia, em 1948. Nesse disco, começou-se a armazenar vinte minutos de música de cada lado. Era usado principalmente para músicas clássicas e rocks nos anos 60, e nas rádios e no comércio eram comuns os discos de 45 r.p.m.. Foi nesse contexto que músicos e compositores viram na gravação uma forma de registrar e copiar boas ideias rapidamente.

Para os músicos e produtores, o LP se tornou a confirmação de que, naquele álbum (com canções interligadas, quarenta minutos de músicas, e outras características que apresentavam o 
compositor) estava a sua obra de arte, na qual o ouvinte podia ter a noção da coleção em apenas um produto. Segundo Marchi, “[...] o LP passa a ser consumido como livro, ou seja, um suporte fechado de coleção em discotecas privadas - com o status de objeto cultural, afinal julga-se a cultura musical de uma pessoa pela discoteca que possui" (MARCHI apud JANOTTI, 2008 p. 87). Mais tarde, a partir dos anos 70, torna-se comum alguns músicos investirem no seu próprio estúdio, em busca de maior liberdade em relação aos pagamentos. "[...] Fica claro que a gravação em estúdio não é somente o registro de uma sonoridade anterior e original (da performance ao vivo); mas sim um processo de criação musical per se, com sua própria estética, valores e referências" (SÁ apud JANOTTI, 2008, p. 86).

A partir do pós-guerra é que acontece o avanço da gravação magnética, possibilitando maior flexibilidade e barateamento nas gravações, além de permitir cortes e edições, junto a uma maior qualidade. Nesse modelo de gravação, o sinal elétrico a ser gravado era emitido por uma fonte, que podia ser microfone, disco ou rádio. Seu armazenamento era realizado em fitas cassete, que começaram a ser comercializadas em 1963, e em uma década tornaram-se um produto de qualidade nas reproduções, barato e de grande ajuda para os músicos que queriam mostrar seu trabalho às gravadoras e aos fãs (SÁ, 2006, p. 7).

É nos anos 60 que se desenvolve um sistema em que os instrumentos e vozes eram gravados separadamente tornando o processo mais diversificado e interessante, além do produtor ganhar destaque, através dos conhecimentos técnicos, trabalhando junto com os músicos.

Nos anos 70 se desenvolvem aparelhos estéreos portáteis que ajudaram na propagação do rap, principalmente entre os afrodescendentes nova-iorquinos, conforme vemos em Sá:

[...] desde os pianos e pianolas para serem tocadas com partituras nos saraus que reuniam as famílias na virada do século XIX; destes aos gramofones e grandes rádios adquiridos para serem ouvidos também na sala residencial, na primeira metade do século XX; aos rádios e toca-discos portáteis que vão ocupando os diferentes cômodos a partir do pós-guerra e permitem aos adolescentes uma escuta musical diferenciada dos pais, em seus próprios quartos, num processo de capilarização, individualização e customização crescente da escuta. Processo que acaba rompendo as fronteiras do lar e acompanha o indivíduo em seu percurso urbano [...] (SÁ, 2006, p. 10).

Depois da popularização das fitas cassetes, devido à facilidade de operação, é criado o sistema ótico, os CDs, onde a gravação, leitura e reprodução sonora são feitas com raios laser. Trata-se de grande avanço nesses aparelhos, que alcançaram maior popularidade no início de 1990. 
A partir disso, acontece "um processo de mudança nos hábitos de consumo baseado na desmaterialização da música" (SÁ, 2006a, p. 324). Ela deixa de ser um suporte físico e passa a ser reproduzida na forma de arquivo digital. Pesquisadores do instituto Fraunhofer, na Alemanha, criaram um formato de arquivo de áudio comprimido, em 1989, visando facilitar a troca de arquivos, popularmente conhecido como MP3. Segundo o jornalista Miguel Sá (2006), a criação do MP3 e o surgimento de redes de cooperação, que permitem a troca de arquivos digitais, fizeram com que as pessoas adquirissem o hábito de fazer download de suas músicas preferidas no computador, remunerando ou não os donos dos direitos autorais. A partir daí começou a era de compartilhamento via internet, com uma distribuição descentralizada de arquivos digitais, fazendo com que a indústria fonográfica, junto com alguns segmentos do entretenimento, fosse à procura desses usuários criadores de redes de troca de arquivos, e os responsabilizasse juridicamente.

Contudo, surgiram também meios legais de distribuição da música na internet, na qual o usuário pagaria pelo download. Como foi crescente o número de usuários à procura de música na $w e b$, grandes empresas como a Sony começaram a buscar uma forma de oferecer música pela internet, por volta do ano 2000 (SÁ, 2006a, p. 327).

Janotti afirma que

[...] os gêneros musicais "linkados" aos jovens, como o pós-rock ou a música eletrônico, estão muito mais associados a uma cultura Shuffle ${ }^{4}$, em que a cultura auditiva é marcada por audição de faixas individuais do que pela apropriação de um álbum como obra marcada pela audição de uma sequência de faixas pré-ordenadas (JANOTTI, 2008, p. 75).

À medida que a internet se tornou o principal meio de comunicação e divulgação dos músicos com seu público, foi necessário uma adaptação nessa área, sendo a criatividade uma oportunidade para as bandas e os músicos se reinventarem privilegiando os shows e não mais a venda de CDs.

\section{Trajetos da produção musical independente no Brasil}

A indústria fonográfica no Brasil sempre carregou um acervo de excelente qualidade. A partir da década de 30, com a popularização do rádio, a música brasileira cresceu muito. Já nos

\footnotetext{
${ }^{4}$ Shuffle marca um modo de audição, em geral associado aos MP3 players, caracterizado pela audição aleatória das faixas armazenadas no tocador e que rompe com o modelo tradicional de audição de LPs e CDs que seguem a sequência linear das faixas e autores dos álbuns musicais.
} 
anos 40, ganhou um cenário nordestino e, também, um novo estilo musical, o samba-canção, com um ritmo mais calmo e orquestrado em que as canções falavam, principalmente, de amor. Entre as composições de música dessas épocas destacavam-se Luiz Gonzaga, Chico Alves, Lupicínio Rodrigues, Noel Rosa, Pixinguinha, Abel Ferreira e Jacob do Bandolim (MÁRIO, 1986. p. 7).

No final dos anos 50 e início dos anos 60, o Brasil passa por significativas mudanças em todos os âmbitos, principalmente no cultural. Nesta época surgem novos movimentos musicais como a Bossa Nova, a Tropicália e a Jovem Guarda. A televisão começa a se popularizar influenciando "o gosto musical" com os grandes festivais musicais, a exemplo do Festival de Música Popular Brasileira organizado pela TV Record. Assim, os antigos ídolos da Rádio Nacional são substituídos por Chico Buarque, Milton Nascimento, Roberto Carlos, entre outros (MÁRIO, 1986. p. 7).

As gravadoras multinacionais continuavam no mercado, mas já não tinham grande audiência devido à intensidade cultural que o Brasil estava vivendo. Com o golpe militar de 64, a música brasileira sofre com a censura e perde seu espaço para as multinacionais. A partir disso, inicia-se o imperialismo cultural, com as músicas estrangeiras dominando as emissoras de rádios, TVs e, principalmente, comprando gravadoras nacionais. Com isso, a música brasileira fica em segundo plano, obrigando-se a se internacionalizar. Cantores brasileiros começam a cantar em inglês, mudam seus nomes - como é o caso de "Light Reflections" da Copacabana, que aparecia em $7^{\circ}$ lugar no segundo semestre de 1972, com compacto "Tell Me Once Again"; ou de Terry Winter, da Beverly, que aparecia em $8^{\circ}$ lugar, com o single "Summer Holiday" (MORELLI, 1991, p.50). Surgiam ídolos efêmeros fabricados pelos meios de comunicação.

Do fato, o predomínio da música estrangeira nas programações das emissoras de rádio e nos suplementos das gravadoras foi registrado pela imprensa até os anos finais da década de 70, quando não era mais possível explicá-lo em função de algum provável efeito devastador da repressão política sobre a criatividade musical brasileira (MORELLI, 1991, p.48).

No final da década de 70, o Brasil já sofre com os impactos da crise econômica e assim traz novos valores musicais que definem a estreia do disco independente. Em 1976, com base em pesquisas da Associação Brasileira de Produtores de Discos, apontava-se que o domínio da música estrangeira parecia menor, embora confirmassem a participação desproporcional de mercado de discos. 
O número de discos independentes aumentou a partir de 1979. Um aumento de 4 para 600 discos em apenas quatro anos competindo com as grandes gravadoras estrangeiras (MÁRIO, 1986, p. 7).

Muitos ídolos da MPB, que já estavam longe das gravações, e artistas relacionados às multinacionais que queriam maior liberdade no trabalho, partiram para os discos independentes. Podemos citar alguns nomes como artista Emilinha Borba, que gravou o LP "Força Positiva", no qual cantou "Meu amor não envelhece", de Arthur Moreira e Osmar Navarro, "O herói da noite", de Renato Barbosa e Míriam Batucada, "Eu vou até de manhã", de Lauro Maia, "O milagre da luz", de Esdras Silva e Klécius Caldas e "Ninguém fica pra semente”, de Vovó Ziza e Noca da Portela.

A grande motivação para o aparecimento de artistas que queriam seguir um caminho alternativo das leis do mercado tradicional foi o pioneiro Antônio Adolfo, com seu disco "Feito em Casa" (1977), que apresenta a possibilidade de gravar de forma independente, tendo autonomia, liberdade e, acima de tudo, enfrentando o monopólio das gravadoras. A partir de 1980, discos independentes atingem uma grande quantidade de cópias vendidas, como o grupo Boca Livre, que conseguiu a atenção de importantes programas de rádio e TV. Além deste grupo, outros nomes se destacaram, como Marisa Gata Mansa, Elomar e Manoel da Conceição. Em seguida, começam as gravações independentes em estados como Minas Gerais, Paraná, Pará e na cidade de Brasília. A produção independente ganha reconhecimento nos meios de divulgação e uma grande participação no mercado nacional.

De acordo com Lobão, sua iniciativa de criar o selo "Universo Paralelo" se deu devido a uma necessidade maior de independência em relação aquilo que era produzido e divulgado, não ficando apenas no âmbito do faturamento comercial. Com o sucesso das produções independentes, as grandes gravadoras criaram dificuldades pressionando músicos e compositores que muitas vezes ficavam impedidos de participar deste tipo de iniciativa.

Apesar dos limites deste tipo de produção, cada vez mais se tem alcançado um público desejoso de novidades no âmbito musical, através do espaço virtual, que cumpre um papel de distribuidor e divulgador de material inédito, com a possibilidade de atingir grande número de pessoas além da fronteira nacional.

\section{Distribuição, divulgação e marketing - a luta por visibilidade}

Antes da internet se tornar uma mídia popular, percebia-se uma grande dificuldade na divulgação de um disco independente devido às dificuldades impostas pelas grandes gravadoras. A programação das rádios e as emissoras de TV mais importantes eram controladas 
e isso se estendia para o comércio de música e distribuição em todo o país. Assim, somente com criatividade e persistência era possível atingir o mercado dominado pelas grandes gravadoras. Mas existiam grandes oportunidades no mercado para conseguir seu espaço.

\begin{abstract}
Ajuda saber que existem brechas no mercado consumidor que podem ser exploradas pelo produtor independente. Há uma parcela do público que já se cansou do "lixo" imposto, seja nacional ou internacional, e que se cansou também dos velhos ídolos que lançam discos anualmente (MÁRIO, 1986, p.25).
\end{abstract}

Segundo Chico Mário, o ideal para o lançamento de um disco era iniciando com um "coquetel de lançamento", convidando pessoas influentes, inclusive a imprensa. Junto ao convite deve ser mandado um "release" do disco e todo material promocional. Assim são possíveis grandes investimentos, principalmente com a venda dos primeiros discos. Com esse retorno de capital, já é possível investir em shows de lançamento. O show é uma forma de divulgar novamente, de mostrar o trabalho do disco agora no palco. Um show precisa ser divulgado de forma eficiente em rádios, TVs, jornais, revistas, locais e nacionais (MÁRIO, 1986. p. 26).

Segundo Lobão, "uma vez o disco pronto, não sabíamos o que fazer com ele, nenhuma gravadora se interessara pelo trabalho. [...] e tudo indicava que, se não fizessem nada, logo iria morrer à míngua." E então a mídia foi um dos principais fatores para que ele conseguisse mostrar seu trabalho e divulgá-lo, no caso, a milhões de brasileiros, no programa do Faustão, além de rádios comunitárias. E como tática para o lançamento, decidiram recolher toda a tiragem anterior da revista onde foi lançado o álbum "A vida é doce", prensar mais cinquenta mil e aguardar a aparição no programa e lançar tudo no dia seguinte. Uma tática que ajudou a vender 97 mil cópias. Situação que incentivou outros artistas a ansiarem que Lobão empreendesse uma revista especializada que lançasse os artistas independentes.

Uma das dificuldades desses referidos artistas é o de conseguirem espaço nas lojas, tendo em vista que muitas já estão comprometidas com as grandes gravadoras, o que dificulta para a gravação independente. Esta dificuldade continua nos dias atuais e aponta o quanto é complexo participar deste mercado de gigantes em que tudo é pensado e controlado. Inclusive excelentes artistas, que já não eram tão interessantes para o império das gravadoras, partiram para a produção independente. É o caso de Emilinha Borba, que em 2003 saiu às ruas para vender seu novo CD "Emilinha Pinta e Borba" (2003), gravado com R\$ 40 mil obtidos com patrocínio da prefeitura do Rio de Janeiro. A cantora disse que nenhuma gravadora quis distribuir nas lojas, assim ela mesma saiu vendendo nas ruas. Cobrava $\mathrm{R} \$ 12$ por exemplar (metade do preço das lojas), sem risco de pirataria. 
"O fundamental para o independente é distribuir e vender seu trabalho de todas as maneiras possíveis, e ainda criar muitas outras formas, partindo para novas prensagens e para a liquidação dos custos. Só então começará a pensar nos lucros" (MÁRIO, 1986. p. 28). O objetivo da divulgação é gerar conhecimento do público-alvo, utilizando tanto das mídias tradicionais (rádio, TV aberta e fechada, shows e espetáculos), como também a internet. Apesar de todo esforço, a garantia de divulgação nas mídias tradicionais nem sempre existe, uma vez que o jabá, principalmente nas emissoras de rádios, impede a democratização da divulgação. O jabá é a verba paga às rádios pelos artistas, promotores e, principalmente, às gravadoras, para garantir que determinadas canções sejam tocadas. Desta maneira as Majors conseguem poder e influência sobre os meios de comunicação dificultando, mais uma vez, a produção independente.

A distribuição depende da forma com que a música será disponibilizada no mercado, pode ser em suporte físico (CD/DVD) ou online. O suporte físico (CD/DVD), se bem distribuído, pode ser o maior fator de lucratividade, mas depende muito dos pontos de venda, transporte, níveis de estocagem, entre outros. O que implica num aumento do preço do produto final e então se torna economicamente inviável. A distribuição para venda online traz inúmeras possibilidades para os selos independentes. No meio online é possível disponibilizar as músicas em sites especializados de comercialização e download, em grandes lojas de departamento ou a chance de montar a própria loja virtual. Como é o caso do selo Revivendo, de Curitiba, que tem seu site desde 1996.

\section{A produção cultural curitibana na criação de espaços independentes}

Atualmente, para auxiliar os produtores, existe a Associação Brasileira de Música Independente, ABMI, fundada em janeiro de 2002, atuando no mercado brasileiro e no exterior, em busca de produção e distribuição da música independente brasileira. Um dos objetivos da associação é circular propostas de divulgação, ofertas comerciais e a distribuição digital do selo.

Para entender esse mercado, segundo a ABMI, a primeira análise a ser feita é a segmentação dos players por porte, dividindo as empresas em Majors e Independentes. Major é toda gravadora que tenha ligação com as grandes empresas mundiais do setor musical (ABMI). No caso do Brasil, a única empresa com capital exclusivamente nacional que se enquadra no segmento de Major é a Som Livre. Já os selos independentes possuem, em conjunto, uma grande participação no mercado, porém só é visível quando se subdivide este 
mercado em nichos a partir de critérios como estilo de música, região geográfica, público-alvo, entre outros.

Aproximadamente $80 \%$ da produção nacional de fonogramas está concentrada na produção independente, o que representa $25 \%$ do total vendido no país. Esses números refletem o poder das grandes gravadoras que em um único álbum pode vender mais de 100 mil copias, enquanto os números das pequenas gravadoras costumam ficar muito abaixo deste percentual (ABMI). Outro ponto a ser levado em consideração é que as pequenas gravadoras já que são voltadas aos pequenos segmentos e nichos, tendem a se concentrar em uma determinada região do país, limitando sua distribuição, a ter uma playlist restrita a um único gênero musical. E isso ocorre, muitas vezes, pela falta de recursos (humanos, mercadológicos, financeiros, know how etc.) para ampliar a distribuição geográfica, os estilos e os públicos trabalhados para que possam competir com as Majors.

Os selos curitibanos independentes sentem dificuldades em entrar e se fixar no mercado pela falta de procura na cidade, o que acaba favorecendo novamente o eixo Rio de Janeiro-São Paulo. A entrevista concedida pelo Selo Revivendo deixa bem claro este tipo de situação. A empresa trabalha com a recuperação de discos de 78 r.p.m. para CDs e está no mercado desde 1987, o que foi difícil devido às grandes gravadoras, porém por serem os únicos no Brasil a trabalhar com a recuperação da música popular brasileira do início do século $\mathrm{XX}$, conseguiram, aos poucos, se fixar no mercado. O Selo Revivendo foi fundado por Leon Barg e se mantinha autonomamente. Atualmente, a procura por CDs é muito menor e Curitiba nunca foi o principal público desse serviço, pois o maior consumo acontece em São Paulo e Rio de Janeiro.

A internet pode ser uma ferramenta poderosa para auxiliar a produção independente curitibana, que se utiliza de sites especializados ou grandes portais, como rraul.com (http://www.rraul.com), uol (http://www.uol.com.br) e o Terra Sonora (http://sonora.terra.com.br). Também é possível divulgar em blogs e redes sociais como MySpace, Lastfm, Youtube e Facebook. A Banda Mais Bonita da Cidade, que atingiu mais de 8 milhões de visualizações no Youtube em menos de 5 meses, é um exemplo de como a internet pode ser favorável na divulgação alternativa. Hoje já o grupo já possui um site (http://www.abandamaisbonitadacidade.art.br), e continua agindo nas redes sociais. No Facebook criou uma fanpage, com informações da banda, contatos da produção e da assessoria de imprensa, e até uma agenda atualizada. Pelo Youtube e twitter a banda faz um pequeno "vídeo-chamada" sempre antes de qualquer apresentação. Através da internet a banda conseguiu verba para a gravação do seu primeiro CD. 
Esse processo de divulgação demonstra a complexidade do cenário atual. Sá destaca alguns exemplos:

\begin{abstract}
O primeiro é o das bandas que divulgam seu trabalho através da internet; para a seguir assinarem contrato com uma gravadora. Esta prática, que tem se tornado a regra, aponta para um passo atrás no que estava sendo tomado como o processo de desintermediação musical. O segundo é o fato de que os fãs de bandas aproveitam as possibilidades de troca gratuita de música baixando álbuns inteiros de seus ídolos para serem ouvidos nos I-pods e afins, conforme ressalta Dantas [...]. Neste caso, a conexão com um universo de escolhas musicais é utilizado para confirmar gastos previamente construídos a partir das subculturas e dos gêneros musicais (SÁ, 2006, p. 14).
\end{abstract}

Em entrevista com a Banda The Betines, formada em 2008, o integrante Lucas Henrique Schalinski contou as principais dificuldades de se manter uma produção independente em Curitiba. A banda começou com a gravação independente principalmente por ter um estúdio na casa de Lucas, e por ser financeiramente viável, pois o custo por hora em uma gravadora sairia muito caro além de ajudar a divulgar o trabalho da banda e para mostrar a algum possível produtor. Para Lucas achar o público-alvo também foi uma das dificuldades, mas a internet ajudou na divulgação, pois chegaram a ter fãs do Rio de Janeiro. De acordo com Lucas, o cenário musical de Curitiba não é muito motivador para a produção independente:

[...] é necessário uma dedicação muito grande e transformar a banda no seu trabalho, e para se manter, muitas bandas precisam de patrocínio até que possam se sustentar sozinhas, além de que os jovens mudam de preferência musical muito mais rapidamente do que antes, o que dificulta ainda mais o processo de divulgação e produção independente (SCHALINSKI, 2011).

Entretanto, num cenário nacional, encontramos leis de incentivo, não propriamente direcionadas à produção musical independente, mas sim ao desenvolvimento da cultura nacional, como é o caso da Lei Rouanet (lei 8.313 de 23/12/91), que oferece incentivos a quem apoiar financeiramente projetos favoráveis à cultura nacional. Para que possa habilitar o patrocínio é necessário que o projeto seja aprovado junto ao Ministério da Cultura. Saindo do cenário nacional, em Curitiba existe a Lei Municipal de Incentivo à Cultura, que ajuda na divulgação dos trabalhos independentes desde que sejam publicações que valorizam a história e as tradições do município, o que neste caso acaba restringindo os produtores, pois é necessário justificar de que modo aquele trabalho/produto contribui para a cidade.

Segundo Estrela Leminski e Téo Ruiz, em sua obra Contra-Indústria, as leis de incentivo à cultura muitas vezes prejudicam estruturas menores em prol das grandes, que já 
deveriam ser contempladas. Apesar de tudo, as leis foram responsáveis por trabalhos independentes de excelente qualidade e que até hoje é uma alternativa para produção.

\section{Considerações finais}

O mercado da música independente sempre passou por diversos acontecimentos para conseguir seu espaço. Desde o início, quando as Majors dominaram a indústria musical brasileira, a produção independente passou por diversas dificuldades, especialmente em relação à ocupação de um espaço de varejo tradicional e ao baixo potencial de comunicação de massa. Por outro lado, conseguimos perceber que através da história vemos oportunidades crescentes, baseadas na internet, que em muitos casos conseguem amenizar as dificuldades apontadas.

Nota-se que Curitiba sofre por não pertencer ao eixo Rio-São Paulo, mas mesmo assim não recebe nenhum estímulo para seguir com as produções independentes. Existe uma enorme dificuldade em encontrar selos independentes na cidade, além de artistas que seguem por esse caminho. De acordo com o site da ABMI, das 106 gravadoras associadas, apenas uma era de Curitiba. Por outro lado é visível a disposição das bandas autônomas que procuram formas alternativas de produzir, divulgar e vender seu trabalho. Conforme na reportagem Novos Rumos da Música, do Programa Plug da RPC, a iniciativa é um fator determinante para que o público tenha conhecimento do seu trabalho, além de torná-lo seu principal objetivo e concentrar-se nele, é necessário muita dedicação e disponibilidade de fazê-lo.

A internet nos mostra a cada dia como é possível tornar esse processo muitas vezes bem mais rápido do que seria se ela não existisse, porém não que esse processo seja menos trabalhoso, pois a interação com seu público-alvo (quando é encontrado) é extremamente importante para a avaliação do conteúdo, em torná-lo conhecido ou não para os demais a sua volta. Percebe-se também que além da relação artista-público ser bem mais acessível e rápida do que antes, a noção de um consumo mais participativo, em relação ao entretenimento, é crescente, pois o usuário participa ativamente no processo de consumo e divulgação dos trabalhos, onde podemos ver vídeos e músicas serem lançadas primeiramente por fãs e/ou pessoas que gostaram do trabalho divulgado.

Por este e outros processos como a lei de incentivo, vemos como Curitiba está aos poucos se destacando neste meio tão competitivo, e que através das tecnologias pode- se então propiciar um ambiente onde a música se torna facilmente presente, apesar de ter-se visto que ainda assim o cenário curitibano não é tão motivador para quem pretende sobreviver somente através da música. 


\section{Referências}

\section{Livros}

LOBÃO. 50 Anos a Mil. Rio de Janeiro: Nova Fronteira, 2010.

SÁ, S. P. A música na era de suas tecnologias de reprodução. São Paulo: 2006.

JUNIOR, J. S. J. Autenticidade e gêneros musicais: valor e distinção como formas de compreensão das culturas auditivas dos universos juvenis. Salvador: 2008

SÁ, M. Livro do ano 2006: A internet e a distribuição de música: uma nova era para a indústria fonográfica. São Paulo. Barsa Planeta Internacional Ltda. 2006a.

MÁRIO, C. Como fazer um disco Independente. Rio de Janeiro, 1986.

MORELLI, R. C. L. Indústria Fonográfica: Um estudo Antropológico. Editora da Universidade Estadual de Campinas. 1991

LEMINSKI, E.; RUIZ, T. Contra-indústria: volume I. 1a ed. Gramofone Produtora Cultural, Curitiba, 2006

SEBRAE/ESPM. Música Independente: Relatório Completo. Janeiro 2008.

ANDERSON, C. A cauda longa: do mercado de massa para o mercado de nicho. Rio de Janeiro: Campus-Elsevier, 2006.

TINHORÃO, J. R. Música popular: do gramofone ao rádio e TV. São Paulo: Ática, 1981.

TOLEDO, H. M. S. Produção independente de música: 1979-2001. 2005. Dissertação (Mestrado em Sociologia) - Departamento de Sociologia da Faculdade de Ciências e Letras da Universidade Estadual Paulista Júlio de Mesquita Filho (UNESP). Araraquara (SP), 2005.

PRESTES FILHO, L. C. (coord.). Cadeia produtiva da economia da música. São Paulo: Itaú Cultural, 2005.

\section{Sites}

SILVA, A. História da indústria Fonográfica. Disponível em: $<$ http://www.culturamix.com/cultura/curiosidades/invencoes/historia-da-industriafonografica> acesso em: 18 out. 2011.

PICCINO, E. Um breve histórico dos suportes sonoros analógicos: surgimento, evolução e os principais elementos de impacto tecnológico. Disponível em: <http://www.followscience.com/library_uploads/a2bc806c3c91168e37f1a89f18350967/302/u m_breve_historico_dos_suportes_sonoros_analogicos.pdf> acesso em: 18 out. 2011. 
Lei Municipal de Incentivo à Cultura de Curitiba. Disponível em: <http://www.historiadocinemabrasileiro.com.br/lei-municipal-de-incentivo-a-cultura-decuritiba/> acesso em: 05 nov. 2011

Gravação $e$ reprodução do som. Disponível em: <http://www.biomania.com.br/bio/conteudo.asp?cod=1966> acesso em: 18 out. 2011 SILVA. A. História da indústria fonográfica. Disponível em: $<$ http://www.culturamix.com/cultura/curiosidades/invencoes/historia-da-industriafonografica> acesso em: 18 out. 2011

Mercado brasileiro de música 2005. Rio de Janeiro, 2006. 44 p. Disponível em: <http://www.abpd.org.br/downloads/Pub_2006_final.pdf>. Acesso em: 26 Set. 2011.

Mercado brasileiro de música 2006. Rio de Janeiro, 2007. 19 p. Disponível em: <http://www.abpd.org.br/downloads/Publi2007_JAN08.pdf>. Acesso em: 26 Set. 2011.

ABMI - Associação Brasileira de Musica Independente (http:// www.abmi.com.br) acesso em 15 out. 2011.

Dicionário cravo abin da música popular brasileira. Disponível em: <http://www.dicionariompb.com.br/> acesso em: 10 out. 2011.

ESTADÃO. Emilinha Borba ataca camelô nas ruas do Rio. Disponível em: <http://www.estadao.com.br/arquivo/arteelazer/2003/not20030807p1629.htm> acesso em: 12 out. 2011.

A Banda Mais Bonita Da Cidade. Disponível em: <http://www.abandamaisbonitadacidade.art.br> acesso em: 19 out. 2011

G1- PARANÁ. Não espere por isso, diz a Banda mais Bonita da Cidade sobre virar Hit. Disponível em: <http://g1.globo.com/parana/noticia/2011/08/nao-espere-por-isso-diz-bandamais-bonita-da-cidade-sobre-virar-hit.html> acesso em: 27 out. 2011.

BLOG FALATÓRIO. O poder das redes sociais - A banda mais bonita da cidade. Disponível em: 〈http://alexandrejr0.blogspot.com/2011/06/poder-das-redes-sociais-banda-mais.html> BM\&A (BRASIL, MÚSICA E ARTES). Agregadores de música digital: FMI - palestra. São Paulo, 2007. Disponível em: <http://www.bma.org.br>. Acesso em: 27 out. 2011.

\section{Vídeos}

PLUG. Novos Rumos da Música. Disponível em: <http://video.globo.com/videos/rpctvplug/v/novos-rumos-da-musica/1685396/\#/Plug!/page/1> acesso em: 07 de nov. 2011. 